\title{
A study on the effects of personality traits on building effective relationships
}

\author{
Seyed Shahab Mousavi ${ }^{a^{*}}$, Fatemeh Nehzat $^{\mathrm{b}}$, Saba Kamali ${ }^{\mathrm{a}}$ and Ashkan Faraji ${ }^{\mathrm{a}}$
}

${ }^{a}$ Department of Management and Accounting, South Tehran Branch, Islamic Azad University, Tehran, Iran ${ }^{b}$ Department of Management, Payame Nour University, Karaj Branch, karaj, Iran

\section{H R O N I C L E}

\section{Article history:}

Received January 24, 2014

Accepted 20 June 2014

Available online

June 252014

Keywords:

Five big personality traits

Effective communication

Openness

Conscientiousness

Extraversion

Agreeableness

Neuroticism

\section{A B S T R A C T}

This paper presents an empirical investigation to measure the effects of five big personality traits on development of effective communication among middle level managers of the first private Iranian bank, Bank Eghtesade Novin, in city of Tehran, Iran. To measure the effects of five big personality traits, the study uses a questionnaire developed by Jackson (1974) [Jackson, D. N. (1974). Personality research form manual. Research Psychologists Press.]. In addition, to measure the impacts of effective communication we use another questionnaire. All questions are designed in Likert scale and Cronbach alphas for two mentioned questionnaires were calculated as 0.92 and 0.74 , respectively. The implementation of Pearson test as well as regression analysis have revealed that there were some positive and meaningful relationship between four personality traits, openness, conscientiousness, extraversion, agreeableness, and effective communication. In addition, there was a negative and meaningful relationship between neuroticism and effective communication.

\section{Introduction}

Building effective communication plays essential role for business development in today's competitive business industry. There are literally various studies on learning the effects of different personality characteristics on business development (Jannesari et al., 2013). Tehran and Khaledi (2014), for instance, examined the effects of big Five factors including openness, conscientiousness, extraversion, agreeableness, and neuroticism on creativity and innovation among selected employees of municipality in city of Tehran, Iran. The study detected negative and meaningful relationship between neuroticism and creativity and innovation, a positive and meaningful relationship between extraversion and creativity and innovation and finally a positive and meaningful relationship between openness and creativity and innovation. However, the study did not find any relationship between agreeableness as well as conscientiousness and creativity \& innovation. Hoseinifar et al. (2011) performed a survey on relationship between creativity and five factors of personality in high school students of Ardabil. They detected that boys were more creative than girls were. In addition, they

*Corresponding author

E-mail addresses: moosavi.shahab@ymail.com (S. S. Mousavi) 
indicated that among five factors of personality, openness to experience, extraversion, agreeableness and conscientiousness were positive predictor of creativity and neurosis was negative predictor of creativity. Yesil and Sozbilir (2013) performed an empirical investigation on the effect of personality on individual innovation behavior in the workplace based on studying the effects of five personality traits. Dehghanan et al. (2014) presented an investigation on the effects of big five personal traits on emotional intelligence on some Iranian firms located in city of Tehran, Iran. They reported a positive and meaningful relationship between four components namely, extraversion, agreeableness, conscientiousness as well as openness and emotional intelligence. Besides, the study detected a negative and meaningful relationship between neuroticism and emotional intelligence. Aziziha et al. (2014) presented a study to measure the impact of personal characteristics including neuroticism, extraversion, openness to experience, conscientiousness and agreeableness on word of mouth advertisement. The study confirmed the positive of effects of neuroticism, extraversion, openness to experience on word of mouth advertisement and the negative impact of agreeableness on word of mouth advertisement. However, the study did not find any meaningful relationship between conscientiousness and word of mouth advertisement.

\section{The proposed study}

This paper presents an empirical investigation to measure the effects of five big personality traits on development of effective communication among middle level managers of the first private Iranian bank, Bank Eghtesade Novin, in city of Tehran, Iran. To measure the effects of five big personality traits, the study uses a questionnaire developed by Jackson (1974) [Jackson, D. N. (1974). Personality research form manual. Research Psychologists Press.]. In addition, to measure the impacts of effective communication we use another questionnaire. All questions are designed in Likert scale and Fig. 1 shows details of proposed study.

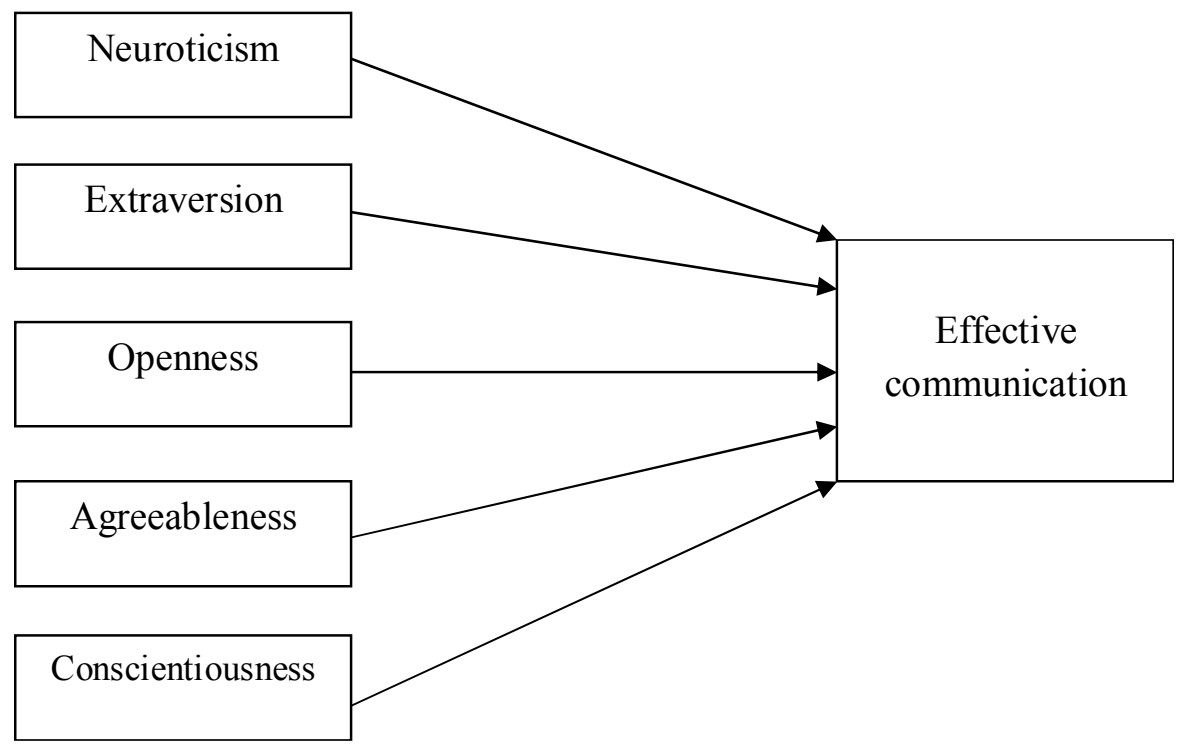

Fig. 1. The proposed study

According to Fig. 1, the following five hypotheses are considered for the proposed study of this paper.

1. There is a negative and meaningful relationship between neuroticism behavior and effective communication.

2. There is a positive and meaningful relationship between extraversion behavior and effective communication. 
3. There is a positive and meaningful relationship between being openness and effective communication.

4. There is a positive and meaningful relationship between agreeableness behavior and effective communication.

5. There is a positive and meaningful relationship between conscientiousness behavior and effective communication.

The sample size is calculated as follows,

$$
N=Z_{\alpha / 2}^{2} \frac{p \times q}{e^{2}},
$$

where $N$ is the sample size, $p=1-q$ represents the probability, $z_{\alpha / 2}$ is CDF of normal distribution and finally $\varepsilon$ is the error term. For our study we assume $p=0.5, z_{\alpha / 2}=1.96$ and $e=0.05$, the number of sample size is calculated as $N=162$. In our survey, $53.9 \%$ of the participants were male and $46.1 \%$ of them were female. Fig. 2 shows details of the personal characteristics of the participants.

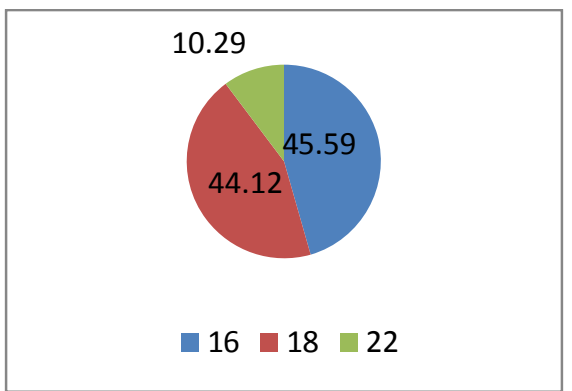

Years of education

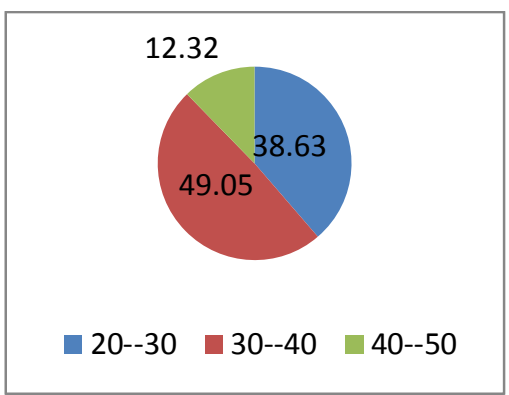

Age

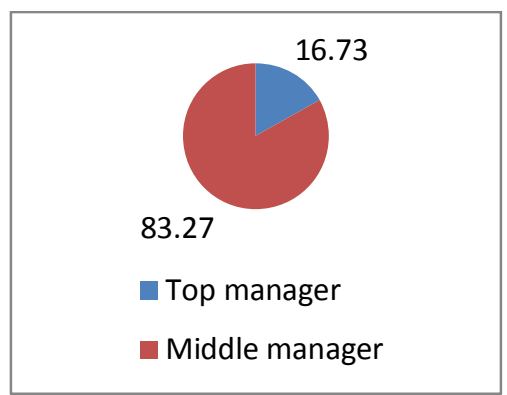

Job position

Fig. 2. Personal characteristics of the participants

As we can observe from the results of Fig. 2, most participants hold good educational background. In addition, they were mostly middle aged people and enrolled in middle level as well as top level management positions. Cronbach alphas for two mentioned questionnaires were calculated as 0.92 and 0.74 , respectively. We have applied Kolmogorov-Smirnov test and the results have indicated that the data were normally distributed. Therefore, we use parametric test to verify the hypotheses of the survey.

\section{The results}

In this section, we present details of our findings on testing the hypotheses of the survey. We first look at Pearson correlation test between different components of five big personality traits and effective communication. Table 1 demonstrates the results of our findings.

\section{Table 1}

The summary of Pearson correlation ratio

\begin{tabular}{llccc}
\hline Hypothesis & Relationship & r & Sig. & Result \\
\hline 1 & Neuroticism $\rightarrow$ Effective communication & -0.238 & 0.002 & Confirmed \\
2 & Extraversion $\rightarrow$ Effective communication & 0.351 & 0.006 & Confirmed \\
3 & Openness $\rightarrow$ Effective communication & 0.337 & 0.010 & Confirmed \\
4 & Agreeableness $\rightarrow$ Effective communication & 0.206 & 0.000 & Confirmed \\
5 & Conscientiousness $\rightarrow$ Effective communication & 0.294 & 0.001 & Confirmed \\
\hline
\end{tabular}


The results of Table 1 confirm all hypotheses of the survey when the level of significance is one percent. In other words, while neuroticism behavior negatively influences on effective communication, being extraversion, openness, agreeableness and conscientiousness influence on effective communication, positively. Table 2 shows the summary of stepwise regression test.

\section{Table 2}

The summary of regression analysis

\begin{tabular}{lccccc}
\hline Variable & Non-standard $\beta$ & Standard error & Standard $\beta$ & t-value & Sig. \\
\hline Intercept & 82.565 & 4.105 & & 20.743 & .000 \\
Extraversion & .571 & .210 & .361 & 4.632 & .000 \\
Openness & .529 & .183 & .242 & 4.152 & .009 \\
Neuroticism & -.416 & .125 & -.197 & -3.090 & .005 \\
\hline
\end{tabular}

R-Square $=0.364$

The results of Table 2 indicate three independent variables, Extraversion, Openness and Neuroticism influence on dependent variable, effective communication. The results of t-value are statistically significant and the sign of coefficients are consistent with the hypotheses of the survey.

\section{Conclusion}

In this survey, we have presented an empirical investigation to study the effects of five personality traits on building effective communication among middle level as well as top-level managers of an Iranian private bank. The survey results have indicated that having Neuroticism attitude negatively influenced on having effective communication. However, being extraversion and openness influence on building effective communication, positively. The results of our findings are consistent with similar studies like Tehran and Khaledi (2014) and Dehghanan et al. (2014).

\section{Acknowledgement}

The authors would like to thank the anonymous referees for constructive comments on earlier version of this paper.

\section{References}

Aziziha, H., Mousavi, S., Tahermanesh, R., Tabatabaee, S \& Mirkamali, E. (2014). An investigation on the effects of personal characteristics on word of mouth advertisement. Management Science Letters, 4(2), 393-396.

Dehghanan, H., Abdollahi, H., \& Rezaei, M. (2014). A study on effect of big five personality traits on emotional intelligence. Management Science Letters, 4(6), 1279-1284.

Hoseinifar, J., Siedkalan, M. M., Zirak, S. R., Nowrozi, M., Shaker, A., Meamar, E., \& Ghaderi, E. (2011). An investigation of the relation between creativity and five factors of personality in students. Procedia-Social and Behavioral Sciences, 30, 2037-2041.

Jackson, D. N. (1974). Personality Research form Manual. Research Psychologists Press.

Jannesari, H., Iravani, M., Masaeli, A., Dareshori, E \& Ghorbani, A. (2013). A social work study on relationship between transactional and laissez-fair leadership style and personality traits: A case study of educational system. Management Science Letters , 3(3), 813-820.

Tehran, G \& Khaledi, F. (2014). An investigation on the effects of personal characteristics on creativity and innovation. Management Science Letters , 4(7), 1495-1498.

Yesil, S., \& Sozbilir, F. (2013). An empirical investigation into the impact of personality on individual innovation behaviour in the workplace. Procedia-Social and Behavioral Sciences, 81, 540-551. 